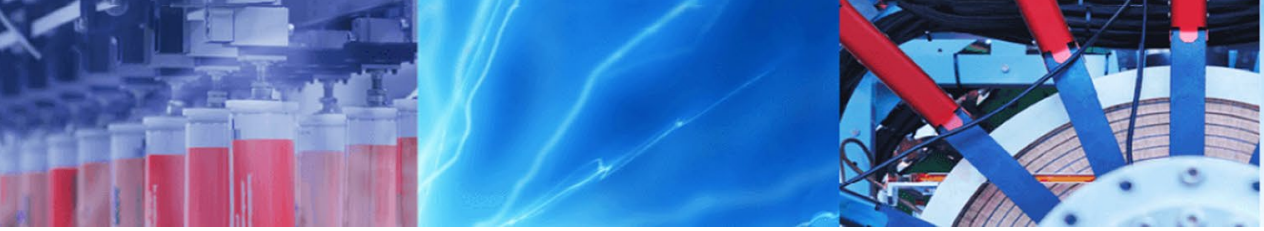

Research Article

\title{
Abrasive wear and optimal installation angle of concrete double-horizontal shaft mixer stirring blades
}

\author{
Hongshen Zhang ${ }^{1} \cdot$ Pan Feng ${ }^{1} \cdot$ Wuquan Ying ${ }^{1}$
}

Received: 7 February 2020 / Accepted: 15 April 2020 / Published online: 12 May 2020

(c) Springer Nature Switzerland AG 2020

\begin{abstract}
The quality of a building desponds directly on the quality of concrete, and mixing is the key process of concrete production. However, a mixing blade is severely worn and has a relatively short life during the mixing process because of severe friction between the concrete material and the double-horizontal shaft mixer stirring blades. This study uses the abrasion mechanism of a mixer and the abrasive wear formula as bases to analyze the theoretical maximum line wear rate $\eta$ of an experimental prototype at five blade installation angles, and obtain the optimal installation interval and optimal installation angle. Results indicate that the wear rate of different blade installation angles changes significantly. The wear rate at $45^{\circ}$ is the largest, and the corresponding theoretical life is only 125 days. By contrast, the wear rate at $35^{\circ}$ is the smallest, and the corresponding theoretical life is 192 days. The change rule of the maximum line wear rate $\eta$ of the blade is obtained through the wear line chart, and the performance curve and evaluation function are fitted using MATLAB. The three aspects of stirring quality, energy consumption, and wear loss are quantitatively analyzed. The best installation angle and interval are $31.8^{\circ}$ and $30^{\circ}-34^{\circ}$. This study can provide a reference for the design choice of the installation angle of the mixing blade of concrete mixers.
\end{abstract}

Keywords Double-shaft concrete mixing $\cdot$ Mixing blade $\cdot$ Maximum line wear rate $\eta$. Optimal installation angle

\section{Introduction}

The rapid development of China's urbanization has resulted in the significant increase in the number of buildings in cities, thereby placing considerably high requirements on the quality of buildings. The quality of concrete directly determines whether the building quality is qualified and has a direct relationship with the mixing effect of mixers. During the mixing process, blade wear is intensified owing to the severe friction caused by the concrete material to the mixing blade, and the mixing effect is significantly reduced with time. Therefore, blade wear should be studied and the optimal blade installation angle of mixers should be determined to reduce loss and improve the mixing quality.
Many institutions have been studying the design and production of twin-shaft forced concrete mixers, such as BHS-Sansohofen Machinery and Mining Company (Germany), Shimao Company (Italy), Jensen Company (US), and Nikkei Co., Ltd. (Japan). Feign researchers have found that the different arrangements of mixing blades in concrete mixing could cause significant differences in the mixing effects. Complex abrasion of stirring blades occurred during the stirring process. Valigi et al. demonstrated and discussed the geometry of an improved planetary concrete mixer blade from the perspective of abrasion resistance, estimated the differences through $2 \mathrm{D}$ evaluation, and evaluated the wear resistance of several new types of blades and extended wear life with reduced wear rate by optimizing new design [1]. Moreover, Valigi et al. used 3D optical

Hongshen Zhang, hongshen@kust.edu.cn | ${ }^{1}$ Faculty of Mechanical and Electrical Engineering, Kunming University of Science and Technology, Kunming 650500, Yunnan Province, China. 
scanners in proposing a new validation procedure of mixing blades in terms of wear resistance and efficiency, and assessed the efficiency and material loss of mixers by using 3D metrological instrument [2], which provides a basis for the selection of blade materials in this paper. Jurevičius et al. analyzed the causes of wear of rotating blade mixers, the most important of which was the adhesion of particles between the blade end and the bottom [3]. This provides a reference for the wear of the stone on the stirring blade in this article. Niranatlumpong et al. proposed a surface wear-resistant treatment for the blades of crushers to provide a reference for the treatment of mixer blades [4]. Tang et al. used a certain type of double-horizontal shaft forced concrete mixer as research object and introduced the calculation formula of the line wear rate of mixing blades on the basis of abrasive wear mechanism. The calculation of the surface line wear rate of mixing blades was obtained through the calculation of the Fluent software and related post-processing [5]. The research provides a basis for the calculation of the line wear rate formula in this paper. At present, the commonly used installation angle of blade is $45^{\circ}$.

Various concrete material mixing methods have different effects on the mixing effect. Ferraris provided an overview of various commercially available mixers and mixing methods for concrete materials. In addition, the advantages and disadvantages of different mixers and mixing methods and their applications were also studied [6]. Rejeb studied the effects of a two-step mixing method on the properties of concrete mixtures containing superplasticizers [7], which provides a theoretical basis for studying the abrasion of the blades caused by the concrete mixing method. Chang and Peng used six mixing methods to prepare high-flow high-performance concrete (HPC). The test results identified one of the most effective and economical methods of manufacturing HPC, particularly for lower binder content, when producing materials with higher fluidity and better compressive strength than other methods, which require minimal mixing time and superplasticizers [8].

Juez et al. studied the friability of recycled concrete aggregate (RCA) during mixing to gain an improved understanding the evolution of this material during mixing and improve the design of recycled aggregate concrete mixtures [9]. Bouzoubaa studied the mechanical properties and durability of concrete made from high-volume fly ash (HVFA) blended cement with coarse fly ash that does not meet the fineness requirements of ASTM C 618. The production of HVFA mixed cement provides an effective method for using coarse fly ash [10]. The pre-mixing procedures of the two-stage mixing approach, such as Tam et al., can effectively develop some strength-enhancing chemical products, including $\mathrm{C}_{3} \mathrm{~S}_{2} \mathrm{H}_{3}$, ettringite, $\mathrm{CH}$, and $\mathrm{C}_{6} \mathrm{~S}_{3} \mathrm{H}$, thereby indicating that RAC made by two-stage mixing approach can improve the hydration process [11]. Kasat et al. developed a comprehensive CFD model to understand solid suspension and its impact on the liquid-phase mixing process in a solid-liquid stirred reactor, and studied the predictive ability of applying CFD technology to a solid-liquid stirred vessel [12]. Mechtcherine et al. used discrete element method (DEM) to simulate concrete flow [13]. Valigi et al. studied the optimization of concrete twinhorizontal mixers in proposing a model that can evaluate the influence of design parameters on machine power consumption in the different stages of the mixing cycle [14].

Cazacliu and Roquet introduced a new concrete mixing dynamics model. This model defines five consecutive phases through which the properties of a mixture can be changed [15]. Cazacliu proposed a model for the relationship between microstructure state evolution and mixing time in concrete components [16]. Danilevskii et al. described a method to monitor the homogeneity of concrete mixture and determine its processability index on the bases of vibration level, sound, and vibration excited in the mixer during the concrete mixing process [17]. Ilesanmi et al. improved the concrete mixer. The results obtained showed that compared with the manual method, the developed concrete mixer has higher operating efficiency, shorter processing time, and higher processing capability [18]. Wallevik and wallevik analyzed the shear rate inside a concrete mixer truck and showed that the shear rate decreased exponentially with the increase in drum loading. The results also showed that for a given drum speed, the shear rate decreased with increase in plastic viscosity and yield stress [19]. Dohi found that large impellers are more effective for solid suspension than triple impeller systems [20]. In order to assess and predict the effects of abrasive wear on typical tillage machine components, Bedolla et al. developed a combined experimental and numerical simulation procedure based on a time- and space-resolved version of the Archard wear equation. The applicability of the aforementioned procedure was demonstrated on a tooth of a circular harrow. The simulated worn geometry was in good agreement with the real geometry of a tooth worn in a soil bin [21]. This provides guidance and basis for corresponding wear modeling in this article.

Machine components operating in sandy environments will wear because of the abrasive interaction with sand particles. In the book of Wen and Huang, a method was derived to predict the amount of wear caused by such abrasive action, in order to improve the maintenance concept of the components [22]. At the same time, a finite element model was used to simulate various tips scratching a smooth surface. The establishment of finite element 
method for scratched surface provides a reference for the establishment of related wear models in this paper. A systematic wear model of the cylindrical grinding process with an alumina abrasive belt from the perspective of single grain sliding wear was established [23]. The results indicated that the established model was in reasonable agreement with the experimental outcomes, which suggests that this model could be useful in the industry to predict the wear process of abrasive belts [24].

The reasonableness of the blade installation angle directly affects the quality and efficiency of concrete. At present, domestic and foreign enterprises have studied the installation angle of mixers mainly from the producers' prospective. The insufficient theoretical bases of designs and imperfection of blade design have become uncertain factors restricting the performance of mixers. On the basis of the theoretical analysis of blade installation angle, the simulation and experimental research on the rationality of blade installation angle can provide theoretical support to the design of the blade installation angle of doublehorizontal shaft mixer and reference for the blade installation angle design of other models.

\section{Wear analysis of stirring blades}

\subsection{Wear mechanism}

Sand and stone during the mixing process of mixers will have a more intense friction with the mixing blade compared with other concrete materials. The blade surface will wear out because of the hardness and irregular appearance of sand and stone, and the rough surface will cause corresponding wear on the blade. These two examples are the main forms of abrasive wear. The force between the sand and stone causes the abrasive to squeeze the blade surface, thereby causing the abrasive to rub against the surface of the object. Abrasive wear damages the blade surface, form grooving abrasion, and generate abrasive debris. During the stirring process, the relative sliding speed of sand on the blade surface will also cause different degrees of wear. Sand is fine-grained and the main form of friction with the blade during the stirring process is rolling friction. Moreover, the diameter of the stone is considerably larger than that of the sand, and the sliding friction mainly occurs during the stirring process. By contrast, stones produce substantially intense friction on the blades. War theory states that the amount of wear is proportional to the size of the abrasive particles, and the particle diameter of stones is considerably larger than that of sand. In addition, sand surface is relatively smooth under long-term water erosion. Therefore, the surface wear caused by stone is evidently serious $[5,22]$.

\subsection{Wear calculation theory}

The foregoing abrasion mechanism indicates that stone is the main abrasive particle that causes the abrasive wear of stirring blades. Accordingly, the corresponding calculation formula of line wear $\eta$ is obtained as follows $[5,22]$ :

$\frac{\mathrm{d} h}{\mathrm{~d} s}=K \frac{p}{H^{\prime}}$

where $\mathrm{d} h$ is the wear thickness of the surface, $d s$ is the relative sliding distance, $K$ is the wear coefficient, $p$ is the surface pressure of the stirring blade, and $H$ is the material hardness of the stirring blade.

Formula (1) indicates that the theoretical line wear rate $\eta^{*}$ of the blade can be derived as follows:

$\eta^{*}=\frac{\mathrm{d} h}{\mathrm{~d} s} \cdot \frac{\mathrm{d} s}{\mathrm{~d} t}=K \cdot \frac{p}{H} \cdot v$.

The volume fraction of stone in concrete is $\zeta$, which can reflect the probability of abrasive wear caused by contacting and sliding between the blades and stones during the mixing process. Hence, the revised blade line wear rate $\eta$ formula is as follows:

$\eta=\eta^{*} \cdot \zeta=\frac{\mathrm{d} h}{\mathrm{~d} s} \cdot \frac{\mathrm{d} s}{\mathrm{~d} t} \cdot \zeta=K \cdot \frac{p}{H} \cdot v \cdot \zeta$,

where $\eta$ represents the revised line wear rate and $v$ is the relative sliding speed.

Formula (2) indicates that when the wear coefficient $K$ is constant, the wear rate is proportional to the load during wear and inversely proportional to the hardness of the blade material. However, results of normal working conditions and some simulation experiments indicate that the abrasive wear coefficient $K$ is not constant. Accordingly, the value of $K$ is related to the relative size between the abrasive entities hardness $(\mathrm{Ha})$ and hardness $(\mathrm{Hm})$ of materials to be grounded. In general, relative wear occurs in three areas: (a) low wear zone, where $1.25 \mathrm{Ha}<\mathrm{Hm}$ and the wear coefficient $K$ is proportional to $\mathrm{Hm}^{-6}$; (b) excessive wear zone, where $0.8 \mathrm{Ha}<\mathrm{Hm}<1.25 \mathrm{Ha}$ and the wear coefficient $K$ is proportional to $\mathrm{Hm}^{-2.5}$; and (c) high wear zone, where $\mathrm{Hm}<0.8 \mathrm{Ha}$ and the wear coefficient $K$ remains constant [22].

The material of the stirring blade was set to gray cast iron with Poisson's ratio of 0.27 , elastic modulus of $66 \mathrm{MPa}$, yield limit of $572 \mathrm{MPa}$, and Brinell hardness of $210 \mathrm{HBS}$. The mixing material is a homogeneous concrete fluid material. The specific material properties are as follows: dynamic viscosity is $100 \mathrm{~kg} /(\mathrm{m} \mathrm{s})$ and density $\rho$ is $2350 \mathrm{~kg} / \mathrm{m}^{3}$. The aggregate is basalt, the density $\rho$ is $3000 \mathrm{~kg} / \mathrm{m}^{3}$, and Brinell hardness is approximately $485 \mathrm{HBS}$. The volume fraction of the aggregate in concrete is $31.6 \%$. Thus, the volume 
fraction of stones in homogeneous concrete in formula (3) is $\zeta=31.6 \%$.

The characteristics of abrasive wear indicate that the ratio of the hardness of the abrasive ( $\mathrm{Ha}=485 \mathrm{HBS}$ ) and hardness of the material to be grounded $(\mathrm{Hm}=210 \mathrm{HBS})$ is 2.31 . Thus, $0.8 \mathrm{Ha}=388 \mathrm{HBS}>\mathrm{Hm}$. Evidently, abrasive wear is in a high wear zone. Its wear coefficient $K$ remains constant (i.e., $K=8 \times 10^{-5}$ ) [6].

\subsection{Pressure and speed distribution of stirring blades}

The stirring blade model is shown in Fig. 1. To facilitate the research, the stirring blades are labeled as shown in the figure.

The calculation results of the symmetrically distributed mechanism are the same owing to the symmetrical relationship of the stirring mechanism. Hence, only the blades on one of the stirring mechanisms are used as research object for the analysis. After processing using the post-processing software Tecplot, the surface pressure distributions of the stirring mechanism at five blade installation angles were obtained, as shown in Fig. 2.

As shown in Fig. 2, the maximum pressure distribution is at the top surface of the stirring blade, and the maximum values at the installation angles of $30^{\circ}, 35^{\circ}, 40^{\circ}, 45^{\circ}$, and $50^{\circ}$ are $14.4,13.1,15.1,16.1$, and $13.5 \mathrm{kPa}$, respectively. The

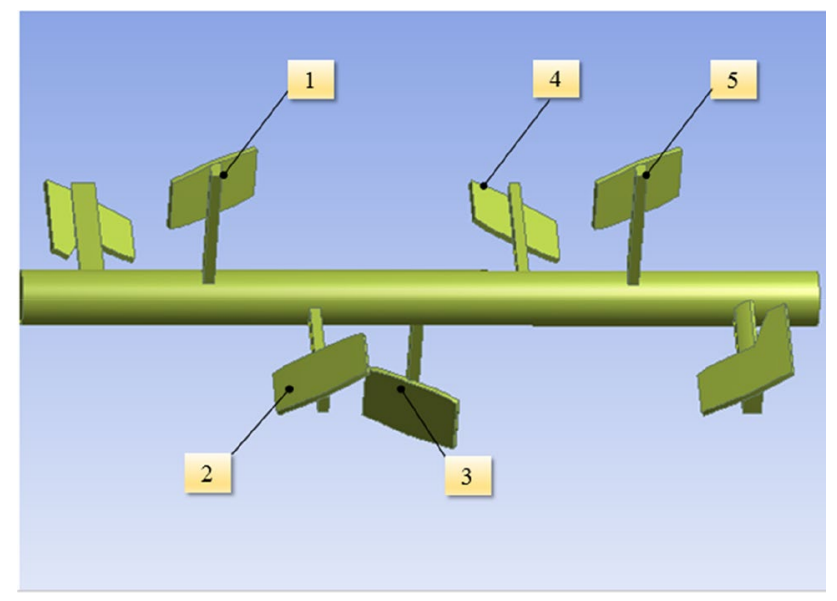

Fig. 1 Schematic of the blades stress distribution cloud diagram also shows the surface pressure change of the stirring mechanism. Note that the pressure at the top of the blade is the highest and the pressure at the root is the lowest based on the different blade installation angles, which is consistent with the actual situation.

The speed of the mixer is $35 \mathrm{rpm}$ under the five installation angles. Hence, the linear velocity distribution of the stirring mechanism is the same. The calculation result of the speed distribution is shown in Fig. 3, which indicates that the maximum speed is approximately $2 \mathrm{~m} / \mathrm{s}$. The speed direction is along the tangential direction of the imaginary circle radius position, where the speed value is located.

The line wear formula shows that obtaining the line wear rate of the stirring blade entails determining the pressure on the blade surface and the relative sliding speed between the stirring blade and the material. During the operation of the mixer, the relative sliding speed is related to the surface speed of the blade and its installation angle. Safety criteria indicate that only the cases where the relative sliding speed and surface pressure are the largest are analyzed. To establish a reference frame with the stirring blade, the instantaneous relative sliding speed $V_{\text {rel }}$ of the material when it hits the stirring blade is analyzed (see schematic in Fig. 4). As shown in Fig. 4, $V_{\text {blade }}$ is the instantaneous speed of the stirring blade and $V_{\text {surf }}$ is the partial velocity of $V_{\text {blade }}$ on the blade surface. Its direction should be opposite to the relative sliding speed, the values are equal, and $\alpha$ is the installation angle of the blade. Therefore, the relative sliding speed $V_{\text {rel }}$ of the stirring blade and the material can be expressed as follows:

$V_{\text {rel }}=-V_{\text {surf }}=V_{\text {blade }} \cdot \cos \left(90^{\circ}-\alpha\right)=V_{\text {blade }} \cdot \sin \alpha$.

The relative sliding speeds can be calculated by substituting the blade installation angles $\alpha=30^{\circ}, 35^{\circ}, 40^{\circ}, 45^{\circ}$, and $50^{\circ}$ into Formula (4) in sequence, thereby providing the following results: $1,1.15,1.29,1.41$, and $1.53 \mathrm{~m} / \mathrm{s}$, respectively.

By combining the obtained surface pressure values, a discrete numerical solution of the line wear rate of the stirring blade can be obtained. As an example, the pressure distribution of the No. 1 stirring blade is shown in Fig. 5. The line wear formula indicates that the line wear rate is proportional to the blade pressure. From the pressure distribution, the most severely worn area is mainly 


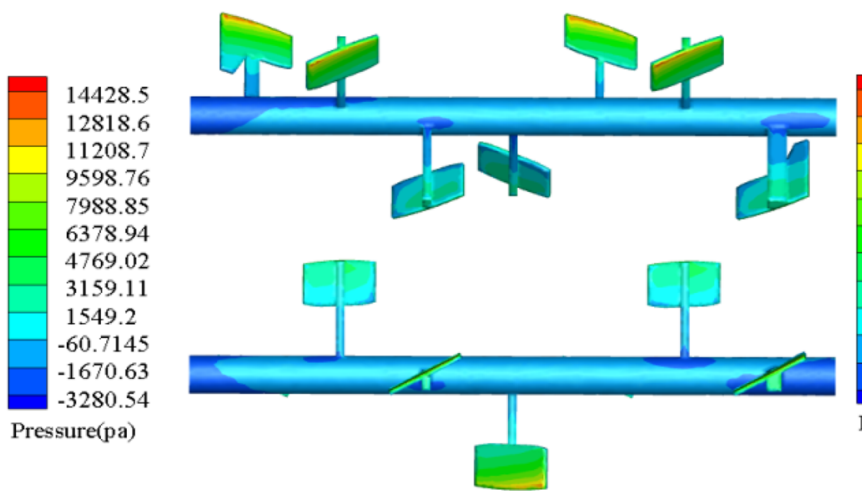

(a) $30^{\circ}$
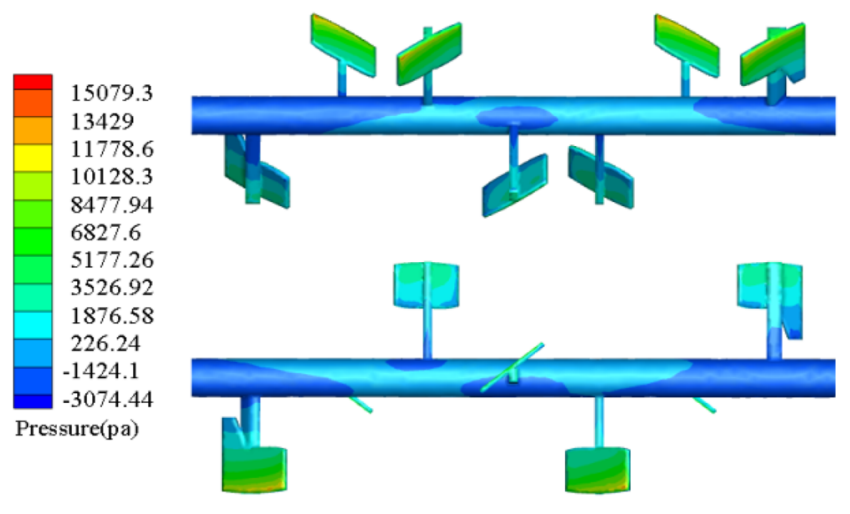

(c) $40^{\circ}$

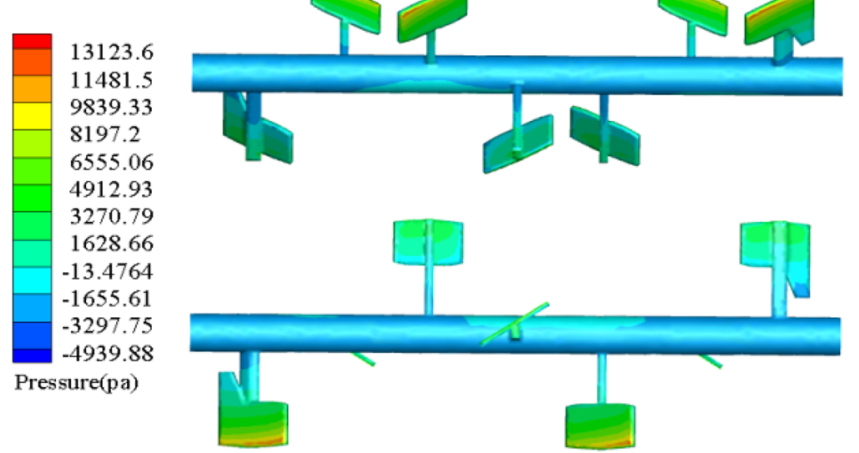

(b) $35^{\circ}$
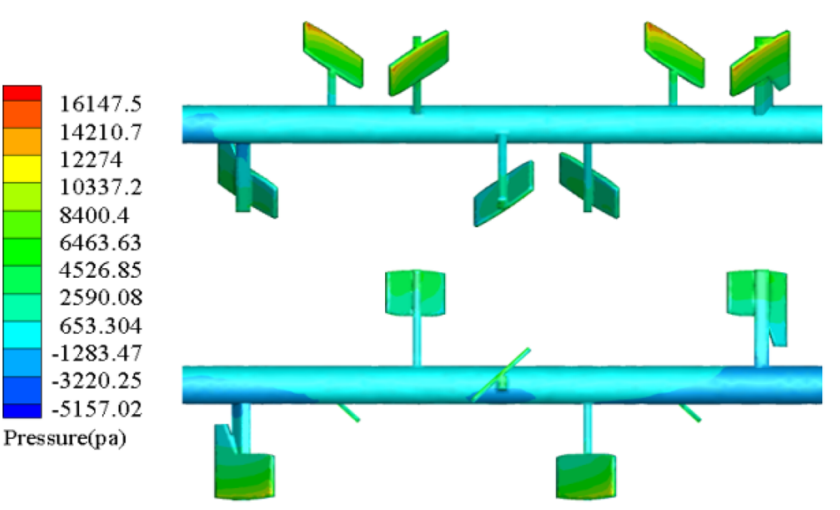

(d) $45^{\circ}$

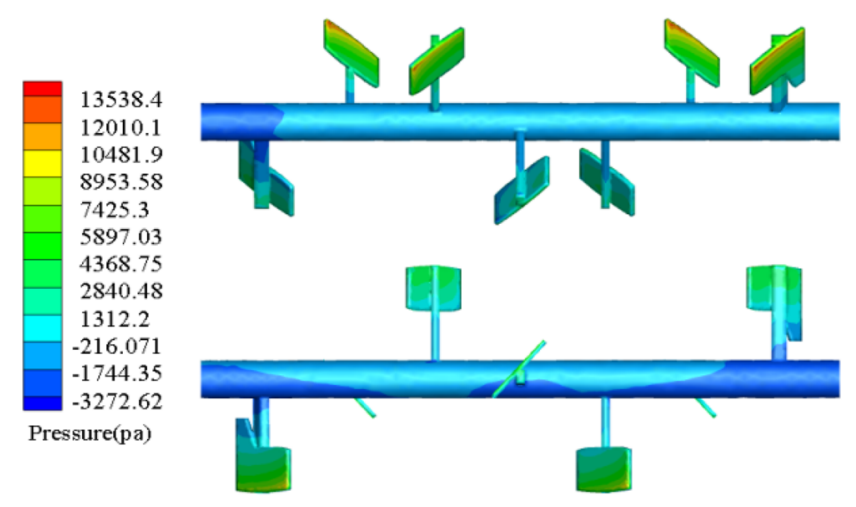

(e) $50^{\circ}$

Fig. 2 Cloud analysis of pressure at different angles 


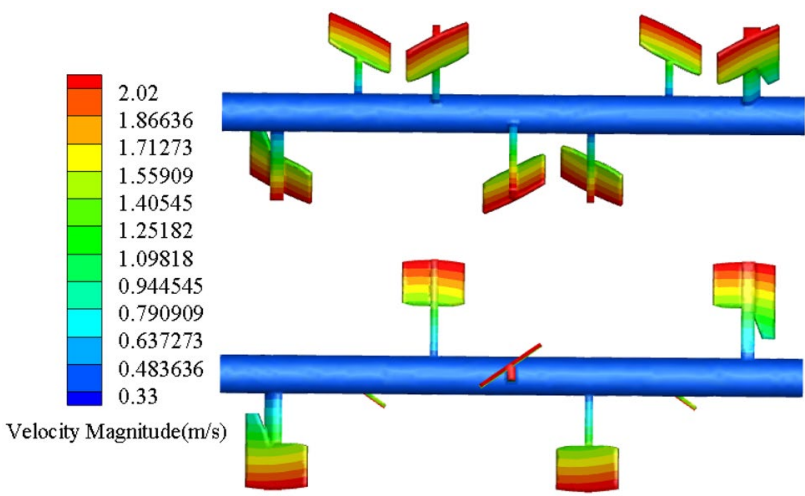

Fig. 3 Cloud speed distribution of the stirring mechanism

concentrated at the top of each stirring blade. The smaller the blade installation angle, the longer the high-pressure equivalence zone of the blade outer edge and the more well-distributed the pressure distribution. By comparing the pressure distribution diagrams, a clear pressure concentration is evident in the upper left corner of the blades at $45^{\circ}$ and $50^{\circ}$, thereby indicating that this area is prone to severe wear.

The blade surface linear velocity and pressure distribution indicate that the maximum wear zone is at the outer edge of the blade's compressed surface (i.e., blade tip). On the basis of the safety criterion, the maximum wear rate can be calculated by taking the maximum pressure value into Formula (3). That is, the service life of the blade mainly depends on the maximum wear rate.

To compare the effects of the blade installation angle on blade life, the change rule of the maximum wear rate of the No. 1 blade under five angles was obtained by using Equation (3), shown in Table 1. Evidently, the relationship between the maximum line wear rate of the blade and installation angle is not a monotonous increase owing to the combined influence of relative sliding speed and surface pressure. The maximum line wear rate of the blade at $45^{\circ}$ is as high as $2.78 \times 10^{-9} \mathrm{~m} / \mathrm{s}$, while the blade line wear rate at $35^{\circ}$ is the lowest at only $1.8 \times 10^{-9} \mathrm{~m} / \mathrm{s}$.

\subsection{Theoretical calculation of blade life}

As shown in Table 1, the maximum line wear rate $\eta$ also changes when the angle changes. By displaying the maximum line wear rate $\eta$ in the form of service life, the performance of the workpiece will be considerably intuitive. Hence, the theoretical service life of the stirring blade is predicted on the bases of the relevant empirical assumptions and prediction analysis.

Hypothetical standards: (1) Blades should be replaced when the maximum wear area at the tip of the blade exceeds $50 \%$ (i.e., vertical wear $>50 \%$ ). (2) The No. 1 stirring blade, which has a thickness of $25 \mathrm{~mm}$, is used as an example. The blade should be replaced when the wear thickness reaches $12.5 \mathrm{~mm}$. The safety criterion indicates that the maximum line wear rate $\eta$ is equal to $1.86 \times 10^{-9} \mathrm{~m} / \mathrm{s}$, which is calculated by the mixer working time for $10 \mathrm{~h}$ per day, 6 days per week, according to Formula (5). The formula for calculating the theoretical life of the blade is as follows:

$I=\left(D \times 50 \% \times 10^{-3}\right) /(10 \times 6 \times 3600 \times \eta)$,

where $I$ is the theoretical life days and $D$ is the blade thickness.

By taking the corresponding parameters into Formula (5), the service life of the No. 1 stirring blade is calculated at approximately 187 days. The same method can be used to estimate the life of other blades. The theoretical life of the No. 1 blade under different installation angles is shown in Fig. 6. Note that the theoretical life of the blade with the lowest wear rate at $35^{\circ}$ is the highest, which is approximately 192 days, and the theoretical life of the blade with the highest wear rate at $45^{\circ}$ is the lowest, which is only 125 days. The other blades have the same theoretical life
Fig. 4 Schematic of the relative sliding between the mixing blade and the material
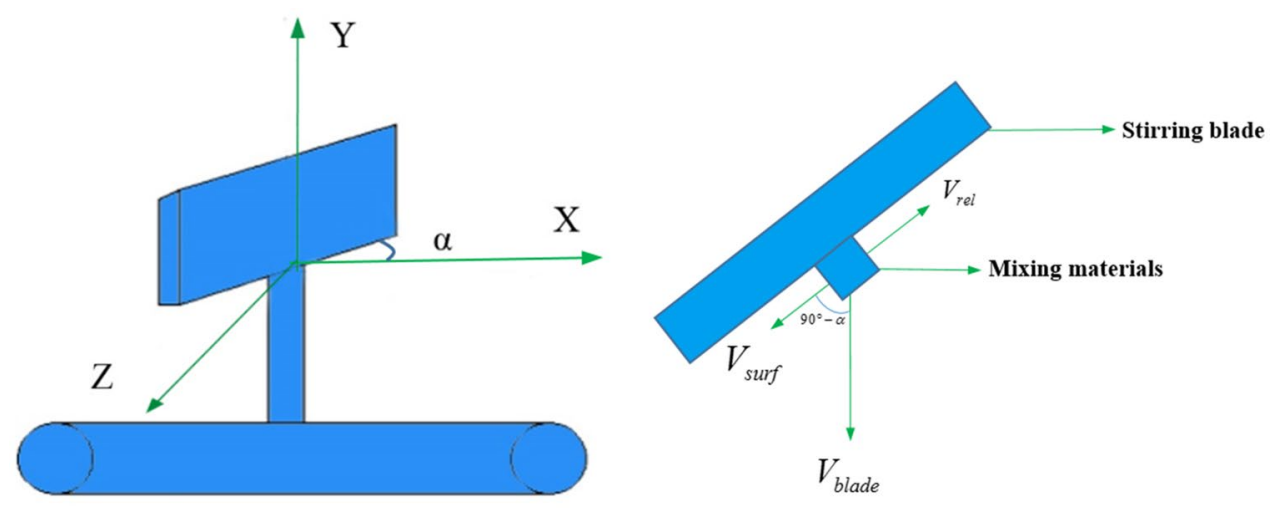


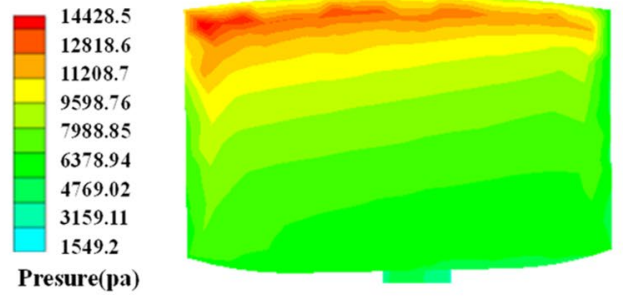

(a) $30^{\circ}$

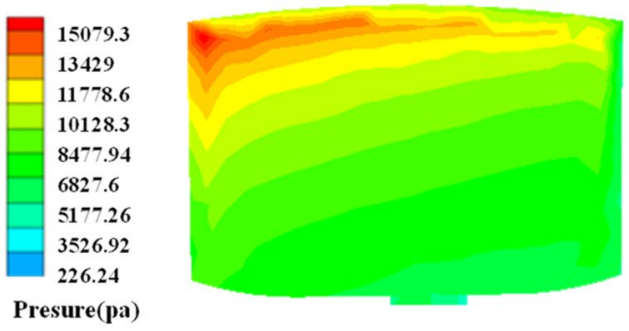

(c) $40^{\circ}$

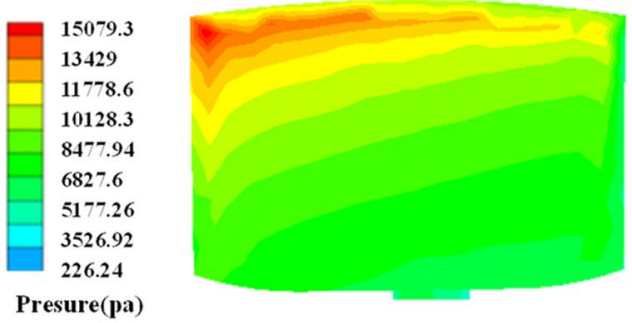

(b) $35^{\circ}$

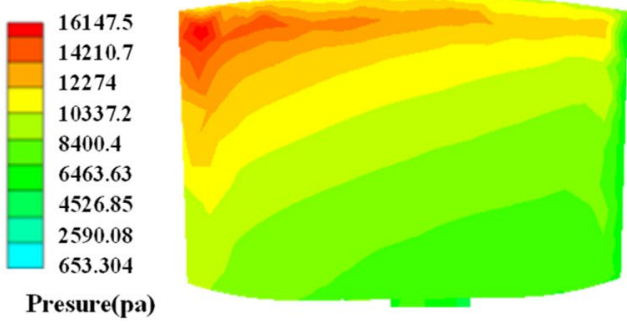

(d) $45^{\circ}$
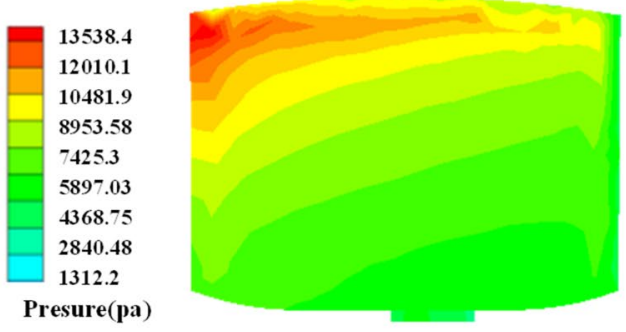

(e) $50^{\circ}$

Fig. 5 Surface pressure distribution of the No. 1 mixing blade at different angles

Table 1 No. 1 mixing blade wear rate of the different installation angles

\begin{tabular}{ll}
\hline $\begin{array}{l}\text { Angle } \\
\left({ }^{\circ}\right)\end{array}$ & Wear rate $\left(\times 10^{-9} \mathrm{~m} / \mathrm{s}\right)$ \\
\hline 30 & 1.86 \\
35 & 1.8 \\
40 & 2.3 \\
45 & 2.78 \\
50 & 2.49 \\
\hline
\end{tabular}

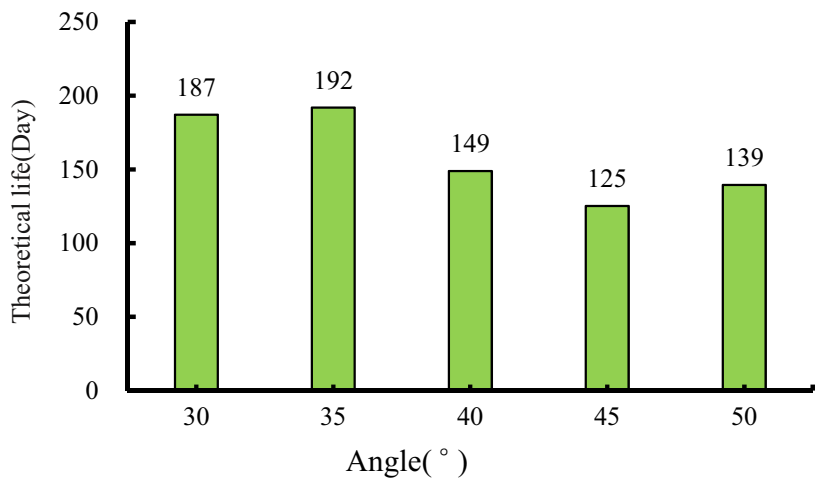

Fig. 6 Theoretical life of the No. 1 blade at different installation angles 
calculation and regularities of distribution as the No. 1 blade. Thus, such calculation will no longer be repeated.

\section{Selection of the optimal blade installation angle based on MATLAB angle selection}

In the author's previous research [25], the average dispersion and power consumption of concrete under different blade installation angles of double-horizontal shafts mixer were obtained, shown in Table 2 and Table 3.

Curve fitting and mathematical modeling are processed using MATLAB to synthesize various performances, such as mixing effect, energy saving and environmental protection, and parts loss; and select the best blade installation angle, thereby providing a quantitative evaluation standard for selecting the blade installation angle.

According to the obtained simulation data, the scatter plots of the average dispersion, energy consumption, and wear rate of the prototype at the different installation angles can be drawn using the MATLAB curve fitting tool (shown in Fig. 7).

According to the fitted curve, the dispersion equation $f_{1}(x)$, energy consumption equation $f_{2}(x)$, and wear equation $f_{3}(x)$ are obtained as follows:

Table 2 Average dispersion at different angles

Table 3 Power consumption at different angles

\begin{tabular}{ll}
\hline Angle $\left(^{\circ}\right)$ & $\begin{array}{l}\text { Average } \\
\text { dispersion }\end{array}$ \\
\hline 30 & 0.167 \\
35 & 0.199 \\
40 & 0.262 \\
45 & 0.319 \\
50 & 0.408 \\
\hline
\end{tabular}

\begin{tabular}{ll}
\hline Angle $\left(^{\circ}\right)$ & $\begin{array}{l}\text { Energy con- } \\
\text { sumption } \\
(\mathrm{kW})\end{array}$ \\
\hline 30 & 22 \\
35 & 21.5 \\
40 & 21.2 \\
45 & 20 \\
50 & 19.2 \\
\hline
\end{tabular}

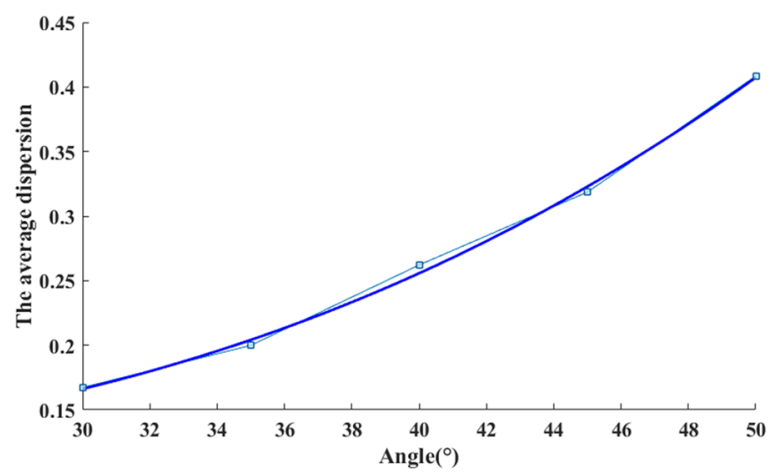

(a) Average dispersion curve fitting

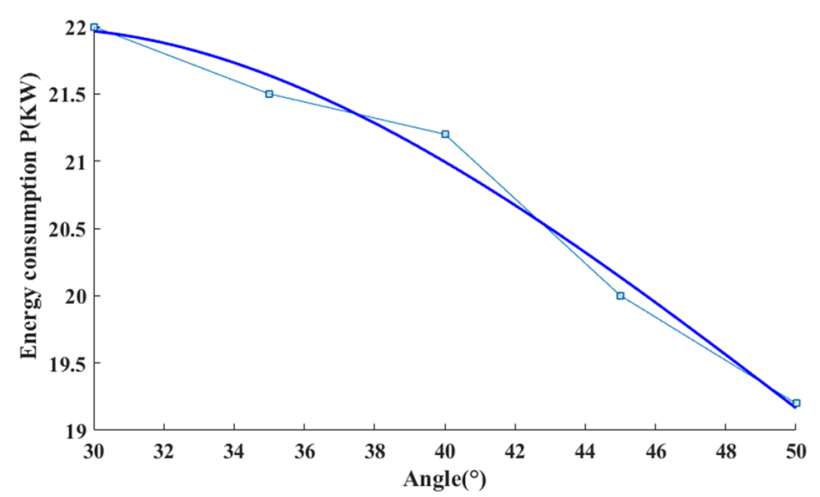

(b) Energy consumption fitting curve

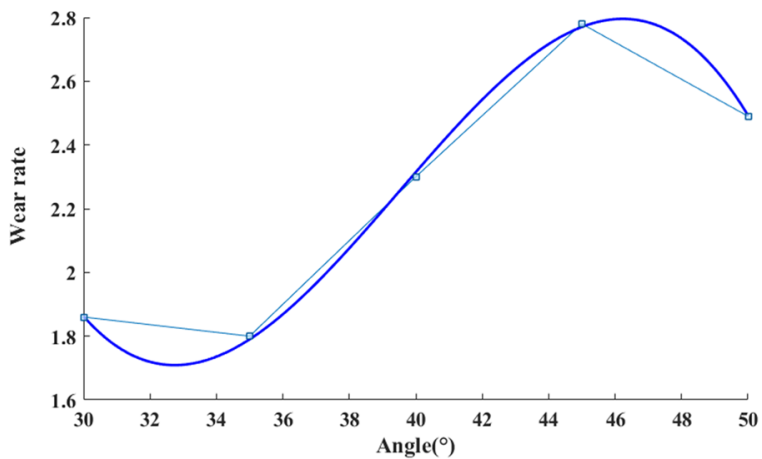

(c) Wear rate fitting curve

Fig. 7 Fitted curves of the average dispersion, energy consumption, and wear rate

$$
\begin{aligned}
y_{1}= & f_{1}(x)=2.505 \times 10^{-6} x^{3} \\
& +9.587 \times 10^{-6} x^{2}-0.001004 x+0.1198
\end{aligned}
$$


$y_{2}=f_{2}(x)=0.0001333 x^{3}-0.02029 x^{2}+0.8295 x+11.74$,

$y_{3}=f_{3}(x)=-0.0008867 x^{3}+0.105 x^{2}-4.026 x+52.06$,

where $x$ is the blade installation angle. The following performance evaluation function $F(x)$ is introduced according to Lagrange's theorem:

$F(x)=\lambda_{1} f_{1}(x)+\lambda_{2} f_{2}(x)+\lambda_{3} f_{3}(x)$,

where $\lambda_{1}, \lambda_{2}$, and $\lambda_{3}$ are the weight factors for $y_{1}, y_{2}$, and $y_{3}$, respectively.

To unify the evaluation index, if we assume that the three weight factors used for the performance evaluation have the same impact on such an evaluation, then the index can be expressed as $\lambda_{1} \Delta y_{1}=\lambda_{2} \Delta y_{2}=\lambda_{3} \Delta y_{3}$. If the evaluation coefficient is assumed to be $\lambda_{1}=1$, then the corresponding values are $\lambda_{2}=0.08607$ and $\lambda_{3}=0.181203$. In practical applications, users can personally define the values of $\lambda_{1}, \lambda_{2}$ and $\lambda_{3}$ to obtain the best installation angle that meets their performance needs.

According to the performance requirements, the three major performance parameters are as small as possible. When $F(x)$ reaches the minimum value, the corresponding installation angle is the optimal one in the current study. The image and the maximum value of the evaluation function $F(x)$ are obtained through MATLAB mathematical processing and image functions (shown in Fig. 8).

The minimum value of $F(x)$ obtained using MATLAB is 2.46 , and the corresponding $x$ value is 31.81 . The optimal installation angle is determined to be $31.8^{\circ}$ under the given evaluation standard. According to the quantitative analysis shown in Fig. 8, the optimal installation angle interval is from $30^{\circ}$ to $34^{\circ}$.

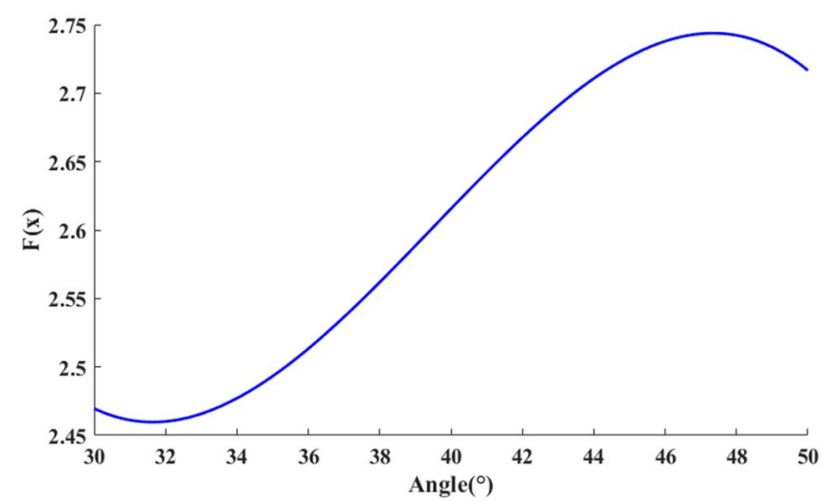

\section{Conclusion}

The theoretical maximum line wear rate $\eta$ of the blades for the five blade installation angles was analyzed, and the theoretical life at five angles was calculated according to the corresponding conversion on the bases of the abrasion mechanism of the mixer and abrasive wear formula. Furthermore, the optimal installation angle and its range were determined.

1. The surface pressure distributions of the stirring mechanism under the five blade installation angles were obtained. The maximum pressure is distributed at the top of the pressure surface of the stirring blade. The maximum values at the installation angles of $30^{\circ}$, $35^{\circ}, 40^{\circ}, 45^{\circ}$, and $50^{\circ}$ are $14,428.5,13,123.6,15,079.3$, $16,147.5$, and $13,538.4 \mathrm{~Pa}$, respectively.

2. The line wear rate $\eta$ of the stirring blade is proportional to the blades pressure. From the pressure distribution, the most severely worn area is mainly concentrated at the top of each stirring blade. The smaller the blade installation angle, the more evenly the pressure distribution. By comparing the pressure distribution diagrams, a clear pressure concentration exists at the upper left corner of the blades at $45^{\circ}$ and $50^{\circ}$, thereby indicating that this area is prone to severe wear.

3. Under the combined influence of relative sliding speed and surface pressure, the relationship between the maximum line wear rate $\eta$ of the blade and installation angle did not increase monotonously. The largest blade line wear rate $\eta$ occurred at $45^{\circ}$ at up to $2.78 \times 10^{-9} \mathrm{~m} / \mathrm{s}$, and the smallest blade line wear rate $\eta$ showed at $35^{\circ}$ but only at $1.8 \times 10^{-9} \mathrm{~m} / \mathrm{s}$. The theoretical life of the blade with the lowest wear rate at $35^{\circ}$ was the highest at approximately 192 days, whereas that with the highest wear rate at $45^{\circ}$ was the lowest at only 125 days.

4. Through curve fitting and mathematical modeling, the optimal theoretical installation angle of the stirring blade was determined to be $31.8^{\circ}$ and the optimal installation interval was from $30^{\circ}$ to $34^{\circ}$.

\section{Compliance with ethical standards}

Conflict of interest The authors declare that they have no conflict of interest.

Fig. 8 Function image of the evaluation function 


\section{References}

1. Valigi MC, Logozzo S, Rinchi M (2016) Wear resistance of blades in planetary concrete mixers: design of a new improved blade shape and 2D validation. Tribol Int 96:191-201

2. Valigi MC, Logozzo S, Rinchi M (2016) Wear resistance of blades in planetary concrete mixers. Part II: 3D validation of a new mixing blade design and efficiency evaluation. Tribol Int 103:37-44

3. Jurevičius J, Sivilevičius H, Spruogis B (2003) Analysis of wearing-out causes for revolving-blade mixers and their reliability improvement. Transport 18(1):40-48

4. Niranatlumpong P, Sukhonket C, Nakngoenthong J (2013) Wear resistant surface treatment of pulverizer blades. Wear 302(1-2):878-881

5. Runqiu Tang, Min Wang, Xiaoli Qi et al (2013) Abrasive wear of double-shaft forced concrete mixer blades. Metall Equip 1:1520 (in Chinese)

6. Ferraris CF (2001) Concrete mixing methods and concrete mixers: state of the art. J Res Natl Inst Stand Technol 106(2):391-399

7. Rejeb SK (1996) Improving compressive strength of concrete by a two-step mixing method. Cem Concr Res 26(4):585-592

8. Chang PK, Peng YN (2001) Influence of mixing techniques on properties of high performance concrete. Cem Concr Res 31(1):87-95

9. Juez JM, Cazacliu B, Cothenet A et al (2016) Recycled concrete aggregate attrition during mixing new concrete. Constr Build Mater 116:299-309

10. Bouzoubaa N, Zhang MH, Malhotra VM (2001) Mechanical properties and durability of concrete made with high-volume fly ash blended cements using a coarse fly ash. Cem Concr Res 31(10):1393-1402

11. Tam VWY, Gao XF, Tam CM et al (2009) Physio-chemical reactions in recycle aggregate concrete. J Hazard Mater 163:823-828

12. Kasat GR, Khopkar AR, Ranade VV (2008) CFD simulation of liquid-phase mixing in solid-liquid stirred reactor. Chem Eng Sci 63(15):3877-3885

13. Mechtcherine V, Gram A, Krenzer K et al (2014) Simulation of fresh concrete flow using discrete element method (DEM): theory and applications. Mater Struct 47:615-630
14. Valigi MC, Logozzo S, Galletti L (2018) Effect of design parameters and operating conditions in concrete twin shaft mixers. In: The international conference of IFToMM ITALY. Springer, Cham, pp 424-431

15. Cazacliu B, Roquet N (2009) Concrete mixing kinetics by means of power measurement. Cem Concr Res 39(3):182-194

16. Cazacliu B (2008) In-mixer measurements for describing mixture evolution during concrete mixing. Chem Eng Res Des 86(12):1423-1433

17. Danilevskii LN, Korobko EV, Terekhov SV (2009) Vibroacoustic monitoring of the homogeneity and workability of concrete mixes by their hydromechanical state in the process of mixing. J Eng Phys Thermophys 82(2):338-345

18. Daniyan Ilesanmi A, Aderoba Adeyemi A, Jimmy Daniel $\mathrm{N}$ et al (2017) Development of a Mixer for concrete production. Am J Eng Technol Manag 2(3):20-24

19. Wallevik JE, Wallevik $\mathrm{OH}$ (2017) Analysis of shear rate inside a concrete truck mixer. Cem Concr Res 95:9-17

20. Dohi N, Takahashi T, Minekawa K et al (2004) Power consumption and solid suspension performance of large-scale impellers in gas-liquid-solid three-phase stirred tank reactors. Chem Eng J 97(2/3):103-114

21. Bedolla PO, Vorlaufer G, Rechberger C et al (2018) Combined experimental and numerical simulation of abrasive wear and its application to a tillage machine component. Tribol Int 127:122-128

22. Wen SZ, Huang P (2017) Principles of tribology, 2nd edn. Tsinghua University Press, Beijing

23. Woldman $M$, Heide EVD, Tinga T et al (2017) A finite element approach to modeling abrasive wear modes. Tribol Trans 60(4):711-718

24. He Z, Li JY, Liu YM et al (2020) Single-grain cutting based modeling of abrasive belt wear in cylindrical grinding. Friction $8(1): 208-220$

25. Wuquan $Y$ (2019) Study on mixing characteristics of double shaft concrete mixer blades. In: Master's thesis, Kunming University of Science and Technology. (in Chinese)

Publisher's Note Springer Nature remains neutral with regard to jurisdictional claims in published maps and institutional affiliations. 